\title{
FRAÇÕES DA MATÉRIA ORGÂNICA DO SOLO APÓS TRÊS DÉCADAS DE CULTIVO DE EUCALIPTO NO VALE DO RIO DOCE-MG ${ }^{(1)}$
}

\author{
Augusto Miguel Nascimento Lima ${ }^{(2)}$, Ivo Ribeiro da Silva ${ }^{(3)}$, Júlio \\ César Lima Neves ${ }^{(4)}$, Roberto Ferreira de Novais ${ }^{(4)}$, Nairam Félix de \\ Barros $^{(4)}$, Eduardo de Sá Mendonça ${ }^{(4)}$, Michelle de Sales Moreira \\ Demolinari $^{(5)} \&$ Fernando Palha Leite ${ }^{(6)}$
}

\begin{abstract}
RESUMO
As mudanças nas distintas frações da matéria orgânica do solo (MOS) sob cultivo do eucalipto são pouco conhecidas. Assim, o presente trabalho teve como objetivo avaliar o impacto do cultivo do eucalipto nos estoques de $\mathrm{C}$ das diversas frações da MOS, em solos ocupados anteriormente por pastagens degradadas, bem como verificar qual fração da MOS constitui-se um indicador mais sensível à mudança de uso do solo. O estudo foi realizado em plantações comerciais de eucalipto em dois locais na região do Vale do Rio Doce-MG (Belo Oriente e Virginópolis), onde foram determinados em amostras dos solos: C orgânico total (COT), C da fração leve (leve livre - FLL e leve oclusa - FLO), da fração pesada (areia-AR, silte + argila -S + A e argila - ARG), da biomassa microbiana (BM) e das frações húmicas (ácidos fúlvicos - FAF, ácidos húmicos - FAH e huminas - FH). Os resultados indicaram que, de maneira geral, os solos sob os diferentes tipos de uso em Virginópolis, em virtude da menor temperatura média anual e maior teor de argila, apresentaram maiores estoques de $\mathrm{C}$ em todas as frações da MOS em relação a Belo Oriente. Assim, o seqüestro de $\mathbf{C}$ no solo pelo cultivo do eucalipto foi maior em Virginópolis $\left(14,2 \mathrm{t} \mathrm{ha}^{-1}\right)$ que em Belo Oriente $\left(10,0 \mathrm{t} \mathrm{ha}^{-1}\right)$, resultando numa taxa de seqüestro de $\mathrm{C}$ de aproximadamente $0,42 \mathrm{e} 0,29 \mathrm{t} \mathrm{ha}^{-1} \mathrm{ano}^{-1}$, respectivamente. Em Belo Oriente, o cultivo do eucalipto favoreceu o aumento no estoque de C das frações ARG, S + A e FH no solo. Comportamento semelhante foi observado para o
\end{abstract}

\footnotetext{
(1) Recebido para publicação em março de 2005 e aprovado em fevereiro de 2008.

${ }^{(2)}$ Doutorando em Solos e Nutrição de Plantas, Departamento de Solos, Universidade Federal de Viçosa - UFV. Av. P.H. Rolfs s/n, CEP 36571-000 Viçosa (MG). Bolsista do CNPq. E-mail: limaufv@yahoo.com.br

(3) Professor do Departamento de Solos, UFV. E-mail: ivosilva@ufv.br

(4) Professor do Departamento de Solos, UFV. Bolsista do CNPq. E-mails: julio_n2003@yahoo.com.br; rfnovais@ufv.br; nfbarros@ufv.br; esm@ufv.br

(5) Estudante de Agronomia, UFV. Bolsista de Iniciação Científica do CNPq.

(6) Engenheiro-Agrônomo, Departamento de Pesquisa em Solos e Silvicultura, Celulose Nipo-Brasileira SA - CENIBRA.
} 
C das FLL, FAF e FAH, em Virginópolis. Dentre todas as frações da MOS analisadas, a BM e a FLO foram indicadores menos sensíveis às alterações na MOS após três décadas da mudança de uso do solo. Com isso, o COT e a fração leve livre, ácidos fúlvicos, ácidos húmicos e humina foram mais eficientes nesse sentido.

Termos de indexação: frações da matéria orgânica do solo, Mata Atlântica, pastagem, eucalipto, uso do solo.

\title{
SUMMARY: SOIL ORGANIC MATTER FRACTIONS AFTER THREE DECADES OF EUCALYPT CULTIVATION IN THE RIO DOCE VALLEY, BRAZIL
}

\begin{abstract}
Little is known about the changes in different soil organic matter (SOM) fractions under short-rotation eucalypt plantations. This study aimed to evaluate the impact of eucalypt cultivation on $C$ stocks of several organic matter fractions in soils previously covered with degraded pasture, as well as to identify which SOM fractions are more sensitive indicators of land use change impacts. The study was conducted at two sites (Belo Oriente and Virginópolis) with commercial short-rotation eucalypt plantations in the Rio Doce Valley region, Minas Gerais state, Brazil. The soil samples were analyzed for: total organic $C$ (TOC), light fraction $C$ (free light - FLL and occluded light- FLO), $C$ associated to heavy fractions (sand $-A R$, silt + clay $-S+A$ and clay $-A R G)$, microbial biomass $C(B M)$ and humic fractions $C$ (fulvic acids-FAF; humic acid-FAH and humin-FH). Results indicate that overall organic $C$ stockst in all SOM fractions were higher in soils of Virginópolis than those of Belo Oriente due to the lower annual mean temperature and higher clay content. Thus, soil $C$ sequestration by eucalypt plantations was higher in Virginópolis $\left(14.2 t \mathrm{ha}^{-1}\right)$ than in Belo Oriente (10.0 t ha-1), resulting in a $C$ sequestration rate of $0.42 t \mathrm{ha}^{-1} \mathrm{yr}^{-1}$ and $0.29 \mathrm{tha}^{-1} \mathrm{yr}^{-1}$, respectively. In Belo Oriente the eucalypt plantations also favored the increase in $C$ stocks of the $A R G, S+A$ and $F H$ fractions. A similar pattern was observed for $C$ of FLL, FAF and FAH in Virginópolis. Of all SOM fractions, the BM and the FLO were the least sensitive indicators of alterations in SOM three decades after land use changes. In this regard, TOC and Cof FLL, FAF, FAH and FH were more efficient.
\end{abstract}

Index terms: organic carbon, Atlantic forest, pasture, eucalypt, soil use.

\section{INTRODUÇÃO}

A matéria orgânica do solo (MOS) é o maior reservatório de $\mathrm{C}$ terrestre se as reservas fósseis não forem consideradas, representando cerca de duas vezes a quantidade de $\mathrm{C}$ da atmosfera e da biomassa vegetal (Swift, 2001). Sua constituição é bastante complexa, sendo formada por diversas frações com tempos de residência variando desde semanas (como a biomassa microbiana) até milhares de anos (como a fração humina). Na maioria dos solos, as formas mais recalcitrantes são dominantes em termos quantitativos e, portanto, constituem um compartimento que desempenha papel crucial no seqüestro do $\mathrm{C}$ em formas estáveis, com prolongado tempo de residência (Stevenson, 1994; Trumbore, 2000). Em cultivos de ciclo mais longo, como é o caso florestal, a MOS parece ser uma das características estreitamente relacionada com a sustentabilidade da produção a longo prazo (Mendham et al., 2004).
A intervenção na vegetação existente durante estebelecimento de culturas anuais, pastagens e florestas comerciais pode levar a um decréscimo nos estoques de MOS graças ao incremento no processo erosivo, aceleração da decomposição, redução no aporte de material vegetal ou diferenças na qualidade dos resíduos. Vários fatores afetam a magnitude e a rapidez com que essas mudanças ocorrem, incluindo a natureza do uso, tipo de solo, clima e vegetação original (Paul et al., 2002). Leite et al. (2003) observaram diminuição no estoque de $\mathrm{C}$ orgânico total e em todas as frações húmicas do solo quando se substituiu a mata nativa (Floresta Atlântica) por cultivos anuais (milho) na Zona da Mata-MG. Guggenberger \& Zech (1999) observaram, na Costa Rica, que a substituição de floresta natural por agricultura resultou numa diminuição no conteúdo da MO particulada, sendo a matéria orgânica associada às frações silte e argila menos alterada em relação à matéria orgânica associada à fração areia e à matéria orgânica leve. 
Esses autores observaram redução na concentração de $\mathrm{C}$ orgânico do solo quando a floresta natural foi substituída por pastagem. Entretanto, resultado oposto foi verificado no Brasil, em solo com 20 anos com pastagem em área anteriormente ocupada por mata nativa (Moraes et al., 1996). Isto se deve, provavelmente, ao bom manejo da pastagem, dando condições para aumento no estoque de $\mathrm{C}$ orgânico do solo.

Em trabalho de revisão, em que foram envolvidos solos de diversas partes do mundo, Guo \& Gifford (2002) não observaram, de maneira geral, mudanças no estoque de $\mathrm{C}$ orgânico do solo quando foi substituída a mata nativa por eucalipto. Mendham et al. (2004) também não observaram diferença na concentração de C orgânico do solo ao comparar plantios de Eucalyptus globulus com idade de 11-14 anos com pastagem na Austrália. No entanto, esses autores observaram que a concentração de $\mathrm{C}$ da matéria orgânica particulada foi maior no solo sob eucalipto, em virtude da maior deposição de resíduo orgânico por essa cultura, podendo ser usada como indicadora mais sensível à mudança de uso do solo (Wu et al., 2004). Leite (2001) encontrou menores teores de $\mathrm{C}$ orgânico total (COT) no solo sob eucalipto (após três ciclos de cultivo) em relação ao solo sob mata nativa na região do Vale do Rio Doce-MG. Os motivos que levaram a resultados distintos entre esses estudos não são evidentes, mas podem incluir diferenças na idade da floresta por ocasião da coleta das amostras, tipo de manejo de solo, clima, dentre outros fatores. Também, não se sabe quais as frações da MOS foram mais alteradas com o cultivo do eucalipto.

O objetivo deste trabalho foi avaliar o impacto do cultivo do eucalipto nos estoques de $\mathrm{C}$ das frações da MOS em relação àqueles sob pastagem e mata nativa, bem como verificar qual fração da matéria orgânica constitui um indicador mais sensível à mudança de uso do solo, em dois locais na região do Vale do Rio Doce-MG.

\section{MATERIAL E MÉTODOS}

Este estudo foi realizado em plantações comerciais de eucalipto localizadas em dois locais no Vale do Rio
Doce-MG, onde o cultivo intensivo de eucalipto iniciou em Minas Gerais: 1. Belo Oriente e 2. Virginópolis. O clima dos dois locais, pela classificação de Köppen, é do tipo Aw (Tropical) e Cwa (Tropical de altitude), respectivamente (Quadro 1).

Em cada localidade, foram selecionadas áreas ocupadas com eucalipto (E. urophylla) por 34 anos (atualmente com seis anos de idade e na quarta rotação, com plantio de mudas clonais), adjacentes a áreas de pastagem e vegetação nativa (floresta estacional semidecidual). Nas primeiras três rotações, o eucalipto (mudas originárias de sementes) foi plantado em áreas ocupadas anteriormente por pastagens. As pastagens foram estabelecidas na década de 30, após a derrubada e queima da floresta nativa, e ficaram sob regime de pecuária extensiva até o final dos anos 60s. Nesse período, as pastagens não receberam correção e fertilização e, freqüentemente, apresentavam uma pressão de pastoreio maior que a capacidade de suporte, o que levou à perda de produtividade. Atualmente, os remanescentes de pastagens encontram-se bastante degradados, com erosão laminar e solo exposto em vários pontos. A gramínea dominante é o capimgordura (Melinis minutiflora). Nesses três tipos de uso, foram selecionados talhões de aproximadamente 10 ha, onde foram coletadas, na meia encosta e na entrelinha do eucalipto, bem como na pastagem e na vegetação nativa, em quatro repetições, amostras compostas de solo (três subamostras cada) nas profundidades de 0-5, 5-10 e 10-20 cm. Em cada talhão e nas profundidades de 0-10 e 10-20 cm, foram coletadas amostras de solo indeformadas com anéis volumétricos para estimar a densidade aparente do solo. Para tal, coletaram-se amostras apenas nessas duas profundidades, tendo em vista a limitação das dimensões do anel volumétrico utilizado.

As amostras foram coletadas na época chuvosa, em fevereiro de 2003, secas ao ar, destorroadas, passadas em peneira com malha de $2 \mathrm{~mm}$, homogeneizadas, obtendo-se terra fina seca ao ar (TFSA). Retiraram-se subamostras para análise textural (Quadro 2).

Dessas amostras, retiraram-se subamostras, que foram trituradas e passadas em peneira de 100 mesh (0,149 mm) para determinação de C orgânico total do

Quadro 1. Caracterização das áreas e dos povoamentos de eucalipto estudados

\begin{tabular}{cccccccc}
\hline Município & Latitude & Longitude & Altitude & Solo & $\begin{array}{c}\text { Temperatura } \\
\text { média anual }\end{array}$ & $\begin{array}{c}\text { Precipitação } \\
\text { anual }\end{array}$ & $\begin{array}{c}\text { Produção do } \\
\text { eucalipto }\end{array}$ \\
\hline & $\mathrm{W}$ & $\mathrm{S}$ & $\mathrm{m}$ & & ${ }^{\circ} \mathrm{C}$ & $\mathrm{mm}$ & $\mathrm{m}^{3} \mathrm{ha}^{-1} \mathrm{ano}^{-1}$ \\
Belo Oriente & $19^{\circ} 14^{\prime}$ & $42^{\circ} 24^{\prime}$ & 250 & $\mathrm{LVA}$ & 25 & 1.163 & 26 \\
Virginópolis & $18^{\circ} 42^{\prime}$ & $42^{\circ} 41^{\prime}$ & 850 & $\mathrm{LV}$ & 22 & 1.153 & 42 \\
\hline
\end{tabular}

LVA: Latossolo Vermelho-Amarelo, LV: Latossolo Vermelho. 
Quadro 2. Granulometria e densidade dos solos estudados

\begin{tabular}{|c|c|c|c|c|c|c|}
\hline Vegetação & Tempo de cultivo & Profundidade & Areia & Silte & Argila & Densidade do solo \\
\hline & ano & $\mathrm{cm}$ & 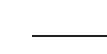 & $\mathrm{g} \mathrm{kg}^{-1}$ & - & $\mathrm{g} \mathrm{cm}^{-3}$ \\
\hline \multicolumn{7}{|c|}{ Belo Oriente } \\
\hline Mata & & $0-5$ & 390 & 70 & 540 & 1,09 \\
\hline Mata & & $5-10$ & 350 & 50 & 600 & 1,09 \\
\hline Mata & & $10-20$ & 360 & 50 & 590 & 1,31 \\
\hline Pastagem & & $0-5$ & 490 & 60 & 450 & 1,31 \\
\hline Pastagem & & $5-10$ & 480 & 60 & 460 & 1,31 \\
\hline Pastagem & & $10-20$ & 420 & 80 & 500 & 1,43 \\
\hline Eucalipto & 34,2 & $0-5$ & 400 & 60 & 540 & 1,37 \\
\hline Eucalipto & 34,2 & $5-10$ & 370 & 30 & 600 & 1,37 \\
\hline Eucalipto & 34,2 & $10-20$ & 350 & 40 & 610 & 1,45 \\
\hline \multicolumn{7}{|c|}{ Virginópolis } \\
\hline Mata & & $0-5$ & 320 & 50 & 630 & 0,87 \\
\hline Mata & & $5-10$ & 320 & 40 & 640 & 0,87 \\
\hline Mata & & $10-20$ & 310 & 30 & 660 & 0,87 \\
\hline Pastagem & & $0-5$ & 300 & 60 & 640 & 0,93 \\
\hline Pastagem & & $5-10$ & 290 & 40 & 670 & 0,93 \\
\hline Pastagem & & $10-20$ & 300 & 50 & 650 & 0,88 \\
\hline Eucalipto & 33,2 & $0-5$ & 260 & 50 & 690 & 0,90 \\
\hline Eucalipto & 33,2 & $5-10$ & 250 & 60 & 690 & 0,90 \\
\hline Eucalipto & 33,2 & $10-20$ & 230 & 60 & 710 & 0,95 \\
\hline
\end{tabular}

solo (COT) pelo método de oxidação via úmida, com aquecimento externo (Yeomans \& Bremner, 1988).

O fracionamento físico da MOS foi realizado, conforme método proposto por Sohi et al. (2001), com algumas adaptações. O método consistiu em agitar manualmente $15 \mathrm{~g}$ de TFSA com $30 \mathrm{~mL}$ de iodeto de sódio $\left(\mathrm{d}=1,8 \mathrm{~g} \mathrm{~cm}^{-3}\right)$ em tubo de centrífuga de $50 \mathrm{~mL}$. Em seguida, centrifugaram-se as amostras a $630 \mathrm{x} g$ por 5 min, e o sobrenadante com a matéria orgânica leve (MOL) foi passado por um cadinho de Gooch acoplado a uma bomba de vácuo para separar a fração leve livre (FLL) que se encontrava junto a agregados do solo. As modificações introduzidas (redução na relação solo:solução e menor velocidade e tempo de centrifugação) foram adotadas após a realização de testes preliminares que mostraram que não havia comprometimento na separação da MOL em relação ao método original. A matéria orgânica retida no cadinho foi lavada abundantemente com água destilada para eliminação do iodeto de sódio e, em seguida, seca em estufa a $65^{\circ} \mathrm{C}$ por $48 \mathrm{~h}$, pesada, macerada em almofariz de ágata para posterior análise. O solo remanescente no tubo de centrífuga foi agitado juntamente com solução de iodeto de sódio $\left(\mathrm{d}=1,8 \mathrm{~g} \mathrm{~cm}^{-3}\right)$ em agitador vertical por $16 \mathrm{~h}$ para promover a quebra dos agregados, sendo, em seguida, centrifugado a $630 \mathrm{~g}$ por $5 \mathrm{~min}$. O sobrenadante foi transferido para cadinho de Gooch acoplado à bomba de vácuo para separar a MOL que se encontrava no sobrenadante, que foi seca em estufa a $65^{\circ} \mathrm{C}$ por $48 \mathrm{~h}$. $\mathrm{O}$ material retido foi pesado, obtendo-se a fração leve oclusa (FLO), que se encontrava intra-agregados. O solo remanescente no tubo de centrífuga foi transferido para recipiente plástico $(500 \mathrm{~mL})$ com $200 \mathrm{~mL}$ de água destilada e foi disperso com $0,5 \mathrm{~g}$ de hexametafosfato de sódio em agitador orbital por 16 h. A fração areia (AR) foi separada por peneiramento (peneira de 0,053 $\mathrm{mm}$ de diâmetro), e as frações de silte $+\operatorname{argila~}(\mathrm{S}+\mathrm{A})$ e argila (ARG) por sedimentação. As frações de silte e argila foram recolhidas em provetas de $2 \mathrm{~L}$, completando-se o volume com água destilada. A suspensão foi agitada durante $30 \mathrm{seg}$, coletando-se imediatamente $25 \mathrm{~mL}$ da suspensão, para obtenção da fração $\mathrm{S}+\mathrm{A}$. A suspensão foi novamente agitada e, então, deixada em repouso pelo tempo necessário para permitir a sedimentação do silte nos $5 \mathrm{~cm}$ superficiais, retirando-se uma amostra de $25 \mathrm{~mL}$ para obter a fração ARG. Esse tempo foi calculado pela aplicação da Lei de Stokes (Klute, 1986). Os teores de C orgânico na FLL e FLO foram determinados por combustão via seca em analisador elementar CHNS (Perkin Elmer). As frações areia (AR), silte + argila $(\mathrm{S}+\mathrm{A})$ e argila $(\mathrm{ARG})$ foram maceradas e submetidas à determinação dos teores de $\mathrm{C}$ orgânico por oxidação via úmida com aquecimento externo (Yeomans \& Bremner, 1988). 
Antes de proceder à determinação do $\mathrm{C}$ da biomassa microbiana (BM), amostras de TFSA foram pesadas e acondicionadas em copos plásticos com tampas perfuradas e então incubadas com $60 \%$ do equivalente de umidade (umidade retida a tensão de $-33 \mathrm{kPa}$ ) em ambiente controlado sob temperatura de $20^{\circ} \mathrm{C}$ por 16 dias, para permitir o restabelecimento da comunidade microbiana. Decorrido esse período, foi feita a determinação do $\mathrm{C}$ da BM pelo método de irradiação-extração (Islam \& Weil, 1998).

Além disso, foram fracionadas as substâncias húmicas, segundo o método sugerido pela International Humic Substances Society (Swift, 1996). Deste fracionamento obtiveram-se as frações: ácidos fúlvicos (FAF), ácidos húmicos (FAH) e huminas (FH), baseando-se na solubilidade em soluções ácidas ou alcalinas. O C em cada fração húmica foi determinado pelo método de oxidação via úmida com aquecimento externo (Yeomans \& Bremner, 1988).

Os estoques de $\mathrm{C}$ nas diferentes frações da MOS nas distintas camadas do solo foram calculados multiplicando-se os teores de $\mathrm{C}$ pela massa de solo da mata nativa com intuito de evitar efeito da compactação do solo nos estoques de $\mathrm{C}$ do solo. A contribuição percentual do $\mathrm{C}$ de cada fração da matéria orgânica do solo foi obtida mediante a divisão do estoque de $\mathrm{C}$ de determinada fração de interesse pelo estoque de COT do solo, e então, multiplicando por 100.

Os resultados obtidos foram submetidos à análise de variância, considerando um delineamento inteiramente casualizado, em que as mudanças no C orgânico, dependendo do tipo de uso do solo (mata nativa, pastagem e eucalipto), em cada profundidade, nos dois locais, foram comparadas por meio de contrastes ortogonais $(\alpha=0,05)$. Essas análises foram realizadas com o programa estatístico SAEG 5.0 (Funarbe, 1993).

\section{RESULTADOS E DISCUSSÃO}

Os solos sob os diferentes tipos de uso em Virginópolis, de maneira geral, apresentaram maiores estoques de $\mathrm{C}$ em todas as frações da matéria orgânica estudadas em relação aos solos sob os diferentes tipos de usos em Belo Oriente (Quadros 3 e 4). Isto provavelmente se deve ao fato de Virginópolis apresentar menor temperatura média anual (Quadro 1), o que implica ciclagem mais lenta que possibilita maior acúmulo de MOS (Tan et al., 2004). Adicionalmente, os solos sob os diferentes usos de Virginópolis apresentaram maiores teores de argila em relação aos de Belo Oriente (Quadros 2), contribuindo para maior proteção física e, ou, coloidal ao C orgânico do solo em virtude da formação de complexos argilo-orgânicos (Six et al., 2002; McConkey et al., 2003; Tan et al., 2004). Na proteção física (estrutural), a matéria orgânica fica retida no interior dos agregados (especialmente microagregados) do solo, enquanto na proteção coloidal ocorre associação íntima dos grupos funcionais da matéria orgânica com os colóides do solo (Christensen, 2001; Caravaca et al., 2004). Watts et al. (2006) também observaram que o valor de COT aumentou com o aumento do teor de argila, sugerindo que a argila oferece proteção física para o $\mathrm{C}$ do solo. Além disso, a produção de biomassa pelo eucalipto em Virginópolis é superior à de Belo Oriente (Quadro 1), o que contribui substancialmente para maior estoque de $\mathrm{C}$ orgânico nos solos daquele local (Leite, 2001).

\section{Carbono orgânico total}

Os efeitos do cultivo do eucalipto nos estoques de COT foram distintos em Belo Oriente e Virginópolis. Em Belo Oriente, o estoque de COT no solo não diferiu significativamente $(p<0,05)$ entre o eucalipto e a pastagem nas profundidades de $0-5$ e $5-10 \mathrm{~cm}$ (Quadro 3). Contudo, o estoque de COT foi inferior para o eucalipto em relação à mata nativa nessas duas profundidades superficiais.

Para Virginópolis, o solo sob eucalipto apresentou maior estoque de COT em comparação ao solo sob pastagem, mas foi menor que o solo sob mata nativa nos primeiros $10 \mathrm{~cm}$ (Quadro 4). Comportamento semelhante foi observado quando foram computados os estoques de $\mathrm{C}$ na profundidade de $0-20 \mathrm{~cm}$, em que o cultivo do eucalipto recuperou os estoques de $\mathrm{C}$ em comparação à pastagem nos dois locais em estudo (Figura 1). O seqüestro de $\mathrm{C}$ em relação a condição inicial (pastagem) foi menor em Belo Oriente $\left(10,0 \mathrm{t} \mathrm{ha}^{-1}\right)$ que em Virginópolis $\left(14,2 \mathrm{t} \mathrm{ha}^{-1}\right)$, resultando numa taxa de seqüestro de aproximadamente 0,29 e $0,42 \mathrm{t} \mathrm{ha}^{-1}$ ano $^{-1}$, respectivamente. Isso evidencia que, em Belo Oriente, o cultivo do eucalipto não se mostrou tão eficiente na adição de COT ao solo quanto em Virginópolis, refletindo mais uma vez, as condições de maior temperatura, menor aporte de material vegetal e menor teor de argila nos solos da primeira. A proteção do C orgânico do solo pela argila tem sido postulada ocorrer através de pelo menos dois mecanismos separados: primeiro, como o C orgânico torna-se humificado, este é quimicamente estabilizado e adsorvido por minerais de argilas com alta superfície específica carregados negativamente; segundo, o $\mathrm{C}$ do solo é fisicamente protegido da mineralização microbiana através da formação de agregados do solo. Adicionalmente, a concentração de argila pode alterar a umidade do solo, alterando tanto a decomposição do $\mathrm{C}$ no solo quanto a deposição de $\mathrm{C}$ no solo via produtividade das plantas (Gama-Rodrigues et al., 2005; Mclauchlan, 2006). Mendham et al. (2002) não observaram diferença na concentração de COT de solos após 7-10 anos de plantio de eucalipto em área anteriormente ocupada por pastagem na Austrália, indicando que, além do tempo de instalação, a condição inicial do solo, o clima e as práticas de manejo exercem grande efeito no COT do solo. Após a primeira rotação com eucalipto, Binkley et al. (2004) não observaram 
Quadro 3. Estoque de carbono orgânico total, das frações leves e pesadas da matéria orgânica, da biomassa microbiana e das substâncias húmicas dos solos da região de Belo Oriente, com respectivas significâncias dos contrastes entre os diferentes tipos de uso do solo

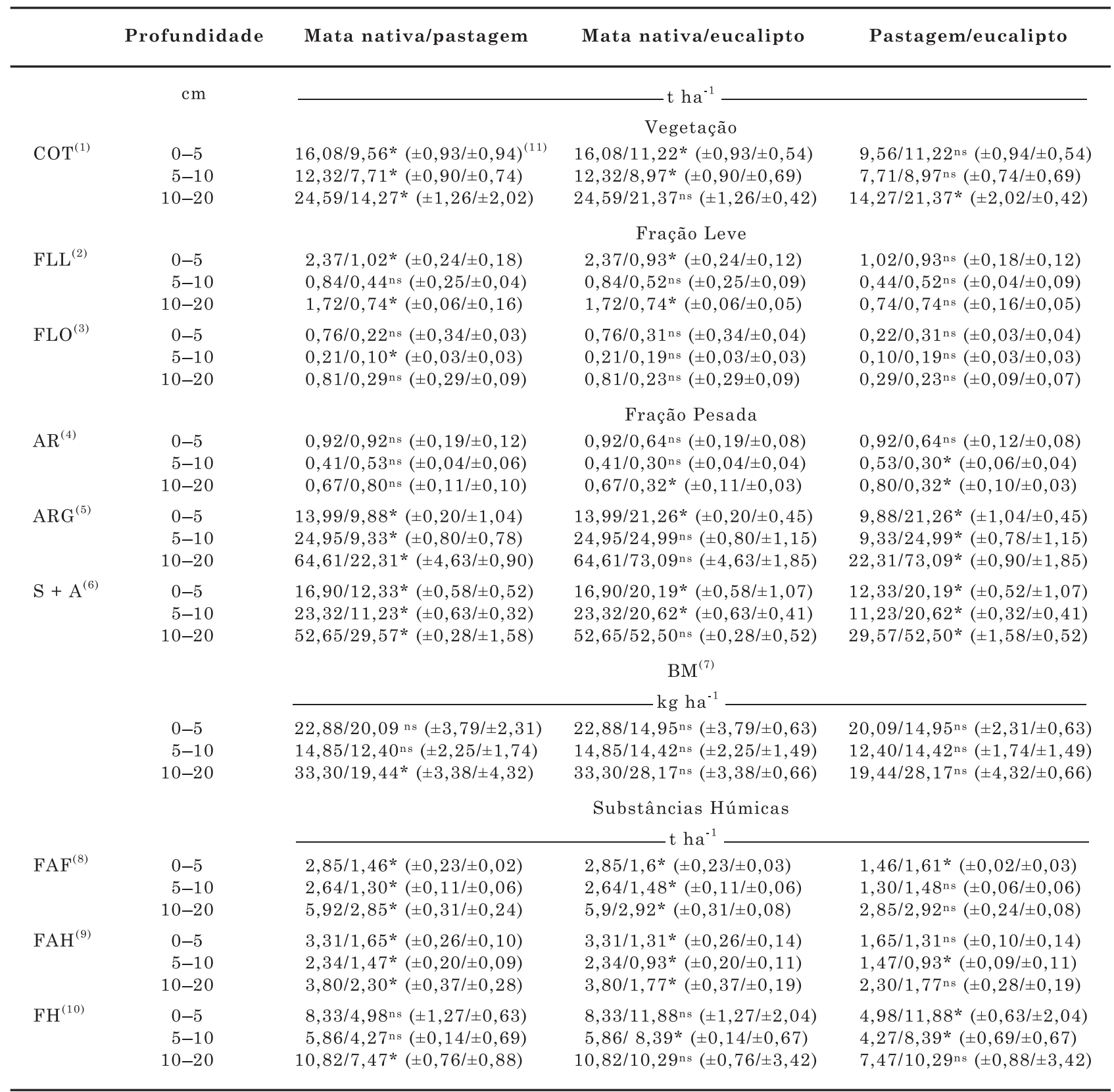

\footnotetext{
(1) Carbono orgânico total. ${ }^{(2)}$ Fração leve livre. ${ }^{(3)}$ Fração leve oclusa. ${ }^{(4)}$ Fração areia. ${ }^{(5)}$ Fração argila. ${ }^{(6)}$ Fração silte + argila. ${ }^{(7)}$ Biomassa microbiana. ${ }^{(8)}$ Fração ácidos fúlvicos. ${ }^{(9)}$ Fração ácidos húmicos. ${ }^{(10}$ Fração huminas. ${ }^{(11)} \pm$ erro-padrão da média/terropadrão da média. ${ }^{\mathrm{ns}}$, *: não significativo e significativo a $5 \%$, respectivamente.
}

mudança significativa no estoque de COT de solo do Hawai, pois as perdas de matéria orgânica derivadas da cana-de-açúcar foram compensadas por aquela adicionada ao solo pelo eucalipto nesse período. Por outro lado, Leifeld \& Kögel-Knabner (2005) observaram que o COT do solo foi um indicador sensível a mudanças rápidas na MOS causadas por diferentes práticas de manejo.

\section{Carbono da matéria orgânica leve e biomassa microbiana do solo}

Em Belo Oriente, não se observou diferença nos estoques de $\mathrm{C}$ da FLL no solo sob eucalipto comparado com aqueles sob o solo de pastagem em todas as profundidades. Para essa mesma fração, o solo sob mata apresentou maiores estoques de $\mathrm{C}$ que aqueles 
Quadro 4. Estoque de carbono orgânico total, das frações leves e pesadas da matéria orgânica, da biomassa microbiana e das substâncias húmicas dos solos da região de Virginópolis, com respectivas significâncias dos contrastes entre os diferentes tipos de uso do solo

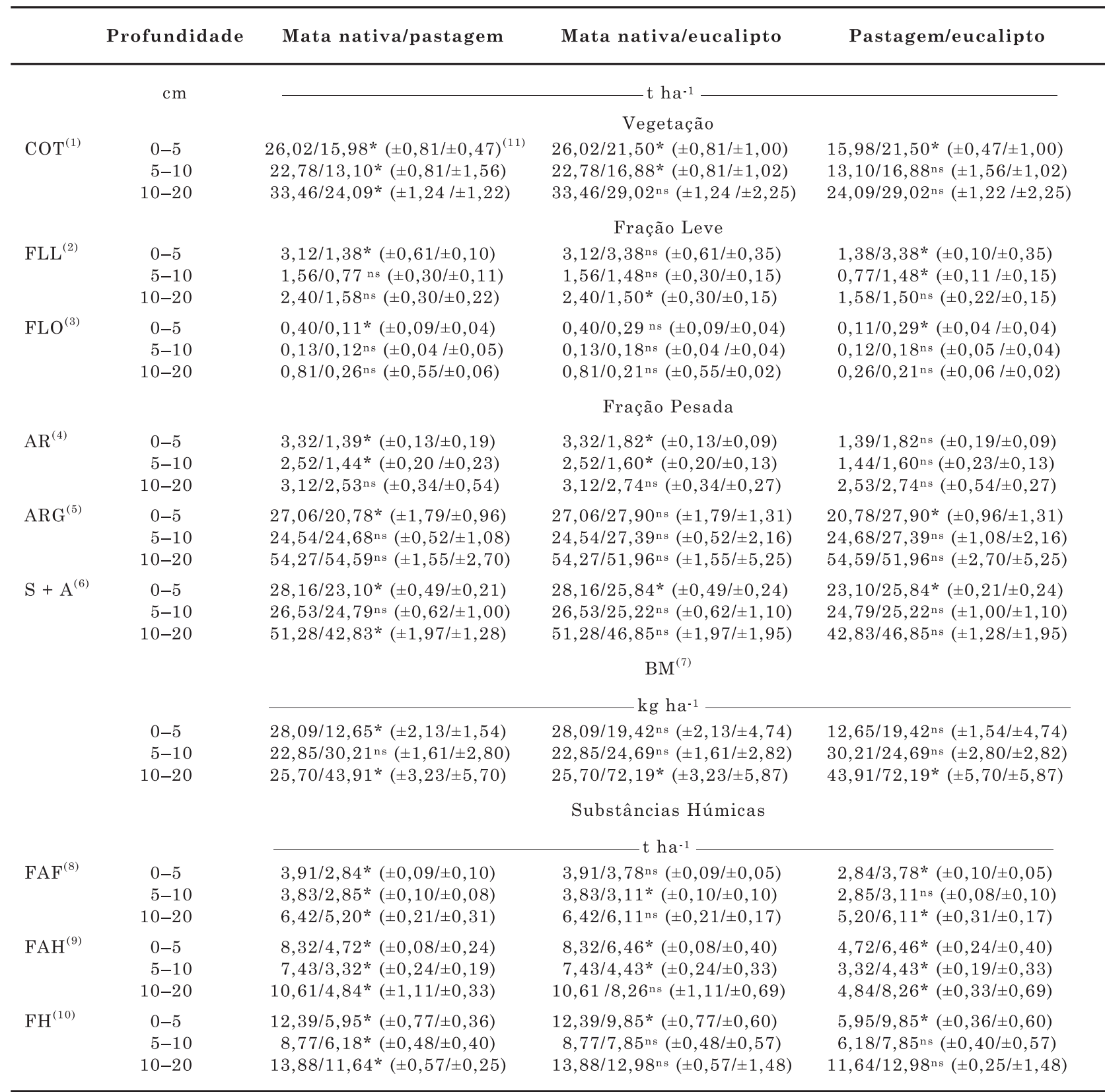

(1) Carbono orgânico total. ${ }^{(2)}$ Fração leve livre. ${ }^{(3)}$ Fração leve oclusa. ${ }^{(4)}$ Fração areia. ${ }^{(5)}$ Fração argila. ${ }^{(6)}$ Fração silte + argila. ${ }^{(7)}$ Biomassa microbiana. ${ }^{(8)}$ Fração ácidos fúlvicos. ${ }^{(9)}$ Fração ácidos húmicos. ${ }^{(10}$ Fração huminas. ${ }^{(11)} \pm$ erro-padrão da média/土erropadrão da média. ${ }^{\mathrm{ns}}$, *: não significativo e significativo a $\mathrm{p}=5 \%$, respectivamente.

sob pastagem e eucalipto nas profundidades de 0-5 e 10-20 cm (Quadro 3). Não foram observadas diferenças no estoque de $\mathrm{C}$ da FLO e da BM, quando se comparou o eucalipto com a mata nativa e a pastagem em todas as profundidades do solo. Assim, para Belo Oriente, a BM não se mostrou um indicador tão sensível de mudanças na qualidade do solo com diferentes usos, como observado por Wu et al. (2004).
Em Virginópolis, o estoque de C da FLL foi maior para o solo sob eucalipto nos primeiros $10 \mathrm{~cm}$ de profundidade em relação ao solo sob pastagem, mas não foi observada diferença em relação ao solo sob mata nesta mesma profundidade (Quadro 4). A FLL é composta basicamente por resíduos vegetais parcialmente decompostos e é fortemente influenciada pela quantidade e qualidade de resíduo depositado no 


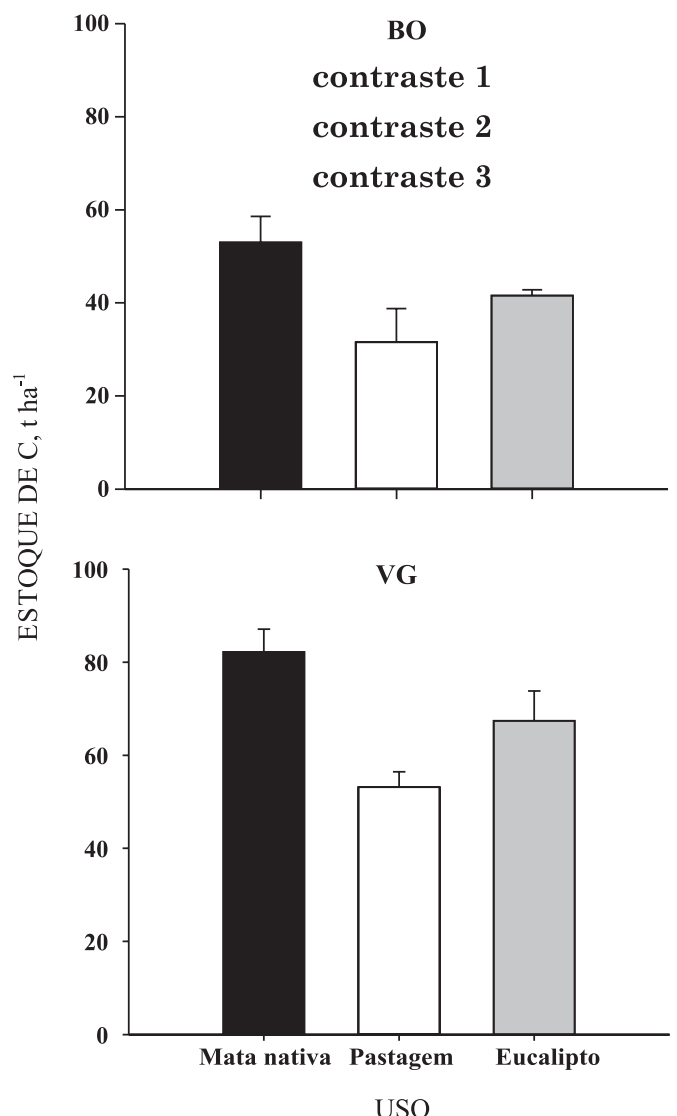

Figura 1. Estoques de carbono orgânico total (COT) na profundidade de 0-20 $\mathrm{cm}$ nos solos sob mata nativa, pastagem e eucalipto em Belo Oriente (BO) e Virginópolis (VG). Contraste 1 (mata nativa vs pastagem), contraste 2 (mata nativa vs eucalipto, contraste 3 (eucalipto $v s$ pastagem). *: significativo a $5 \%$. As barras de desvios verticais representam o desvio-padrão da média $(n=4)$.

solo (Six et al., 2002). Assim, esses incrementos da fração FLL, principalmente nas camadas superficiais nos solos sob eucalipto, em comparação à pastagem, refletem a maior deposição de resíduos, que, ao contrário da pastagem, ocorre principalmente na superfície do solo. Essa recuperação da FLL é importante, pois, embora seu estoque seja bem menor que outras frações mais estáveis da MOS, ela constitui compartimento com rápida ciclagem e que pode favorecer a biota do solo. Não houve diferença no estoque de $\mathrm{C}$ da FLO quando se comparou o solo sob eucalipto com o solo sob pastagem e com o solo sob mata nas profundidades de 5-10 e 10-20 cm. Também não se detectaram diferenças nos estoques de $\mathrm{C}$ da $\mathrm{BM}$ quando se comparou o solo sob eucalipto com os solos sob pastagem e mata nas profundidades de 0-5 e 5-10 cm, mas observou-se maior valor no solo sob eucalipto em comparação com os solos sob mata e pastagem na profundidade de 10-20 cm (Quadro 4).
Como no presente estudo o eucalipto sucedeu a pastagem e como nesta o estoque de C da FLL foi menor do que na mata, isso indica recuperação do estoque de C da FLL pelo cultivo com eucalipto dos solos anteriormente ocupados por pastagens degradadas. Ou seja, a ciclagem de $\mathrm{C}$ pelo eucalipto fica bem evidente nas camadas mais superficiais $(0-10 \mathrm{~cm})$. Isso mostra que a FLL pode ser utilizada como indicador sensível para detectar mudanças na qualidade do solo com diferentes usos e manejos (Six et al., 2002; Wu et al., 2004), embora nem sempre essa superioridade seja constatada (Leifeld \& KögelKnabner, 2005).

\section{Carbono nas frações pesadas da matéria orgânica do solo}

Em Belo Oriente, não foram detectadas grandes diferenças nos estoques de $\mathrm{C}$ da fração $\mathrm{AR}$ do solo conforme o uso (Quadro 3). O solo sob eucalipto apresentou menor estoque de $\mathrm{C}$ dessa fração nas profundidades de 5-10 e 10-20 cm, quando comparado ao solo sob pastagem. Quando comparado ao solo sob mata nativa, o solo sob eucalipto apresentou menor estoque de $\mathrm{C}$ na fração $\mathrm{AR}$ apenas na camada de 10$20 \mathrm{~cm}$. Quanto à fração S + A, maiores estoques foram verificados para o solo sob eucalipto em relação ao solo sob pastagem em todas as profundidades analisadas. O mesmo comportamento foi observado para o eucalipto em relação à mata nativa na profundidade de $0-5 \mathrm{~cm}$, sendo, por sua vez, inferior na profundidade de $5-10 \mathrm{~cm}$.

Em Virginópolis, o estoque de $\mathrm{C}$ da fração AR foi maior nas duas camadas mais superficiais do solo sob mata em relação aos demais usos (Quadro 4). Entretanto, não houve diferença quando se comparou o solo sob eucalipto com o solo sob pastagem. Quanto ao estoque de $\mathrm{C}$ da fração $\mathrm{S}+\mathrm{A}$, notou-se maior valor no estoque de C dessa fração na profundidade de $0-5 \mathrm{~cm}$ no solo sob eucalipto em comparação ao solo sob pastagem. No entanto, o solo sob mata apresentou maior estoque de $\mathrm{C}$ nessa fração em comparação ao solo sob eucalipto nessa mesma profundidade. Pôde-se observar que, nas duas regiões, os estoques de $\mathrm{C}$ na fração areia são bastante pequenos, quando comparados com os das frações mais finas (silte + argila). Além disso, de modo geral, observou-se que os estoques de $\mathrm{C}$ da fração $\mathrm{S}+\mathrm{A}$ foram maiores no solo sob eucalipto em comparação ao solo sob pastagem, mas ainda permanecendo inferior no solo sob mata nativa, indicando que o cultivo do eucalipto tem possibilitado gradual recuperação dessas frações da matéria orgânica. Vários trabalhos têm demonstrado que a maior proporção da MOS está associada às frações mais finas do solo (Freixo et al., 2002; Mando, et al.; 2005) e que a formação de complexos argilo-orgânicos auxilia na preservação da MOS, e isso é especialmente importante nas associações entre óxidos de $\mathrm{Fe}$ e $\mathrm{Al}$ e compostos orgânicos (Bayer et al., 2002). Em geral, solos mais argilosos apresentam maiores estoques de $\mathrm{C}$ no solo e menor taxa de mineralização (Bird et al., 2003). 
Dessa forma, a textura do solo, além de sua mineralogia, é um dos componentes definidores do potencial de seqüestro de $\mathrm{CO}_{2}$ atmosférico (Six et al., 2001).

\section{Substâncias húmicas}

Dentre as diferentes frações húmicas da MOS, observou-se que, em Belo Oriente, os estoques de C das FAF e FAH no solo sob mata foram maiores em comparação àqueles sob os solos de pastagem e eucalipto em todas as profundidades estudadas (Quadro 3). O solo sob mata, por ser um ambiente em que não há perturbações oriundas de práticas de manejo, tais como preparo para plantio e colheita do eucalipto, e onde o processo erosivo, ao contrário da pastagem, é minimizado, tem condições de manter maior estoque de $\mathrm{C}$ nessas frações. Em estudo realizado na Austrália, Chen et al. (2004) observaram que a substituição de mata nativa por cultivo de pinheiro (Araucaria cunninghamii) com 51 anos de idade resultou na diminuição do estoque de $\mathrm{C}$ da $\mathrm{FAF}$, enquanto o estoque de $\mathrm{C}$ da $\mathrm{FAH}$ ficou inalterado. Isso mostra que a FAF é mais sensível à mudança de uso do solo em relação à FAH. Por outro lado, não houve diferença no estoque de $\mathrm{C}$ da $\mathrm{FH}$ entre o solo sob mata e eucalipto nas profundidades de 0-5 e 10-20 cm. Já o solo sob eucalipto apresentou maior estoque de $\mathrm{C}$ das FAF e FH na camada mais superficial do solo (0$5 \mathrm{~cm}$ ) em relação ao solo sob pastagem, refletindo a natureza da deposição mais superficial de resíduos mais lignificados.

Em Virginópolis, de modo geral, o solo sob mata apresentou maior estoque de C da FAF e da FAH nas profundidades até $10 \mathrm{~cm}$ em comparação ao solo sob eucalipto (Quadro 4). Em estudo realizado na Espanha, foi verificado que o solo sob mata apresentou maior estoque de $\mathrm{C}$ na FAF e FAH em comparação ao solo sob cultivo agrícola (Caravaca et al., 2004). No entanto, não foi constatada diferença no estoque de $\mathrm{C}$ na $\mathrm{FH}$ entre esses dois tipos de uso do solo nas camadas de 5-10 e 10-20 cm. Ainda em Virginópolis, quanto à comparação envolvendo eucalipto e pastagem, observou-se maior estoque de $\mathrm{C}$ da FAF nas profundidades de $0-5$ e $10-20 \mathrm{~cm}$ no solo sob eucalipto. $\mathrm{O}$ mesmo comportamento foi observado para a $\mathrm{FAH} \mathrm{e}$ $\mathrm{FH}$ em todas as profundidades e na profundidade de $0-5 \mathrm{~cm}$, respectivamente. Isto pode ser explicado pela deposição de resíduos orgânicos mais lignificados e com o tempo de cultivo com eucalipto, dando condições para os microrganismos atuarem na sua decomposição, favorecendo a humificação. Em estudo realizado em solos da Áustria, Alemanha e Itália, foi constatado um decréscimo da relação $\mathrm{C} / \mathrm{N}$ com a diminuição do tamanho das partículas minerais do solo, refletindo a mineralização e humificação da matéria orgânica do solo (Stemmer et al., 1998). Esses compostos mais humificados apresentam maior complexidade bioquímica, a qual, juntamente com a sua associação com as frações (silte e argila) do solo (estabilização coloidal), dificulta sua decomposição por microrganismos e favorece sua estabilização no solo (Six et al., 2002).
Em Belo Oriente, a maior parte do C está associado às frações mais humificadas do solo (Quadro 3). De modo geral, o cultivo do eucalipto acarretou diminuição do estoque de $\mathrm{C}$ das frações lábeis da MOS (FLL, AR, FAH) ao mesmo tempo que aumentou o estoque de $\mathrm{C}$ das frações mais estáveis (ARG, S + A, FH). De igual importância foi a mudança que ocorreu na proporção entre as SH presentes: o estoque de $\mathrm{C}$ na fração huminas aumentou de 47,2 \% no solo sob mata para $53,0 \%$ no solo sob pastagem e $73,6 \%$ no solo sob eucalipto. Em Virginópolis, tais mudanças não foram observadas, e a proporção de $\mathrm{C}$ na $\mathrm{FH}$ permaneceu em torno de 42,6-45,5\%. As condições mais favoráveis aos processos de decomposição e a menor taxa de aporte de resíduos florestais em Belo Oriente levam à permanência de formas mais estáveis da MOS, tal como a FH que está intimamente associada aos colóides inorgânicos do solo (Stevenson, 1994). Caravaca et al. (2004) também verificaram que, na Espanha, a maior proporção da MOS estava associada às frações húmicas e, nos solos submetidos a cultivo mais intensivo (culturas anuais), houve aumento na proporção da FH em comparação ao solo sob floresta. Nos solos com cultivos anuais, a FH ainda se mostrava mais resistente à oxidação química e, portanto, mais estável que nos solos sob floresta. Em solos altamente intemperizados, como nos do presente estudo, essa estabilização de SH se dá, provavelmente, pela adsorção dos compostos orgânicos pelos óxihidróxidos de $\mathrm{Fe}$ e $\mathrm{Al}$ (Bayer et al., 2002). Existe ainda a possibilidade de que parte do $\mathrm{C}$ orgânico acumulado na FH seja derivada de carvão, conforme constatado recentemente por Hopmans et al. (2005). Embora os plantios atuais de eucalipto sejam feitos sob cultivo mínimo, a queima de resíduos florestais após a colheita foi procedimento rotineiro nas primeiras três rotações na área em estudo. Isso tem implicações na retenção do $\mathrm{C}$ no solo, visto que as frações mais humificadas são mais estáveis e de maior tempo de residência.

\section{CONCLUSÕES}

1. Virginópolis apresentou menor temperatura média anual e maior teor de argila no solo além de maiores estoques de $\mathrm{C}$ em todas as frações da MOS em comparação a Belo Oriente.

2. O cultivo do eucalipto em áreas anteriormente ocupadas com pastagens mal manejadas promoveu a recuperação nos estoques de COT nos dois locais em estudo. Também, em Belo Oriente, o eucalipto favoreceu o aumento no estoque de $\mathrm{C}$ das frações $\mathrm{ARG}$, $\mathrm{S}+\mathrm{A}$ e $\mathrm{FH}$ no solo, enquanto, em Virginópolis, favoreceu o aumento no estoque de C das FLL, FAF e FAH.

3. O C da BM e da FLO foram indicadores pouco sensíveis de mudanças na MOS após a instalação do eucalipto. Com isso, o COT e as frações FLL, FAF, FAH e FH foram mais eficientes nesse sentido. 


\section{AGRADECIMENTOS}

Os autores são imensamente gratos aos três revisores anônimos, pelas suas valiosas sugestões, que contribuíram para a melhoria deste trabalho. Reconhecem o suporte financeiro do CNPq-Conselho Nacional de Desenvolvimento Científico e Tecnológico, por meio de fomento a projetos de pesquisa aos Profs. Ivo Ribeiro da Silva, Nairam Felix de Barros e Roberto Ferreira de Novais, e da FAPEMIG - Fundação de Amparo a Pesquisa do Estado de Minas Gerais, por meio de fomento à projetos de pesquisa aos Profs. Ivo Ribeiro da Silva e Roberto Ferreira de Novais. Agradecem à CENIBRA-Celulose Nipo-Brasileira SA, pela disponibilização das áreas de cultivo para amostragem e pelo apoio logístico.

\section{LITERATURA CITADA}

BAYER, C.; MIELNICZUK, J.; MARTIN-NETO, L. \& ERNANI, P.R. Stocks and humification degree of organic matter fractions as affected by no-tillage on a subtropical soil. Plant Soil, 238:133-140, 2002.

BINKLEY, D.; KAYE, J.; BARRY, M. \& RYAN, M.G. Firstrotation changes in soil carbon and nitrogen in a Eucalyptus plantation in Hawaii. Soil Sci. Soc. Am. J., 68:1713-1719, 2004

BIRD, J.A.; van KESSEL, C. \& HORTWATH, W.R. Stabilization of 13C-Carbon and immobilization of 15N-Nitrogen from rice straw in humic fractions. Soil Sci. Soc. Am. J. 67:806816, 2003.

CARAVACA, F.; LAX, A. \& ALBALADEJO, J. Aggregate stability and carbon characteristics of particle-size fractions in cultivated and forested soils of semiarid Spain. Soil Till. Res., 78:83-90, 2004.

CHEN, C.R.; XU, Z.H. \& MATHERSB, N.J. Soil carbon pools in adjacent natural and plantation forests of subtropical Australia. Soil Sci. Soc. Am. J., 68:282-291, 2004.

CHRISTENSEN, B.T. Physical fractionation of soil and structural and functional complexity in organic matter turnover. Eur. J. Soil Sci., 52:345-353, 2001.

FREIXO, A.A.; MACHADO, P.L.O.A.; GUIMARÃES, C.M.; SILVA, C.A. \& FADIGAS, F.S. Estoques de carbono e nitrogênio e distribuição de frações orgânicas de Latossolo do Cerrado sob diferentes sistemas de cultivo. R. Bras. Ci. Solo, 26:425-434, 2002.

FUNDAÇÃO ARTHUR BERNARDES - FUNARBE. SAEG Sistema para análise estatística. Versão. 5.0. Viçosa, MG, 1993.

GAMA-RODRIGUES, E.F.; BARROS, N.F.; GAMARODRIGUES, A.C. \& SANTOS, G.A. Nitrogênio, carbon e atividade da biomassa microbiana do solo em plantações de eucalipto. R. Bras. Ci. Solo, 29:893-901, 2005.
GUGGENBERGER, G. \& ZECH, W. Soil organic matter composition under primary forest, pasture, and secondary forest succession, Región Huetar North, Costa Rica. For. Ecol. Manag., 124:93-104, 1999.

GUO, L.B. \& GIFFORD, R.M. Soil carbon stocks and use change: A meta analysis. Global Change Biol., 8:345-360, 2002.

HOPMANS, P.; BAUHUS, J.; KHANNA, P. \& WESTON, C. Carbon and nitrogen in forest soils: Potential indicators for sustainable management of eucalypt forests in SouthEastern Australia. For. Ecol. Manag., 220:75-87, 2005.

ISLAM, K.R. \& WEIL, R.R. Microwave irradiation of soil for routine measurement of microbial biomass carbon. Biol. Fert. Soils, 27:408-416, 1998.

KLUTE, A. Physical and mineralogical methods. In: KLUTE, A., ed. Methods of soil analysis. Part 1. 2.ed. Madison, American Society of Agronomy/Soil Science Society of America, 1986. p.383-409. (Agronomy, 9)

LEIFELD, J. \& KÖGEL-KNABNER, I. Soil organic matter fractions as early indicators for carbon stock changes under different land-use? Geoderma, 124:143-155, 2005.

LEITE, F.P. Relações nutricionais e alterações de características químicas de solo da Região do Vale do Rio Doce pelo cultivo do eucalipto. Viçosa, MG, Universidade Federal de Viçosa, 2001. 72p. (Tese de Doutorado)

LEITE, L.F.C.; MENDONÇA, E.S.; NEVES, J.C.L.; MACHADO, P.L.O. \& GALVÃO, J.C.C. Estoque de carbono orgânico e seus compartimentos em Argissolo sob floresta e sob milho cultivado com adubação mineral e orgânica. R. Bras. Ci. Solo, 27:821-832, 2003.

MANDO, A.; QUATTARA, B.; SÉDOGO, M.; STROOSNIJDER, L.; QUATARA, K.; BRUSSAARD, L. \& VANLAUWE, B. Long-term effect of tillage and manure application on soil organic fractions and crop performance under Sudano-Sahelian conditions. Soil Till. Res., 80:95-101, 2005.

McCONKEY, B.G.; LIANG, B.C.; CAMPBELL, C.A.; CURTIN, D.; MOULIN, A.; BRANDT, S.A. \& LAFOND, G.P. Crop rotation and tillage impact on carbon sequestration in Canadian prairie soils. Soil Till. Res., 74:81-90, 2003.

McLAUCHLAN, K.K. Effects of soil texture on soil carbon and nitrogen dynamic after cessation of agriculture. Geoderma, 136:289-299, 2006.

MENDHAM, D.S.; HEAGNEY, E.C.; CORBEELS, M.; O'CONNELL, A.M.; GROVE, T.S. \& McMURTRIE, R.E. Soil particulate organic matter effects on nitrogen availability after afforestation with Eucalyptus globulus. Soil Biol. Biochem., 36:1067-1074, 2004.

MENDHAM, D.S.; O'CONNELL, A.M. \& GROVE, T.S. Organic matter characteristics under native forest, long-term pasture, and recent conversion to eucalyptus plantations in Western Australia: Microbial biomass, soil respiration, and permanganate oxidation. Aust. J. Soil Sci., 40:859$872,2002$. 
MORAES, J.F.L.; VOLKOFF, B.; CERRI, C.C. \& BERNOUX, M. Soil properties under Amazon forest and changes due to pasture installation in Rondônia, Brazil. Geoderma, 70:63-81, 1996.

PAUL, K.I.; POLGLASE, P.J.; NYAKUENGAMA, J.G. \& KHANNA, P.K. Change in soil carbon following afforestation. For. Ecol. Manag., 168:241-257, 2002.

SIX, J.; CONANT, R.T.; PAUL, E.A. \& PAUSTIAN, K Stabilization mechanisms of soil organic matter: Implications for C-saturation of soils. Plant Soil, 241:155176,2002

SIX, J.; GUGGENBERGER, G.; PAUSTIAN, K.; HAUMAIER, L.; ELLIOTT, E.T. \& ZECH, W. Source and composition of soil organic matter fractions between and within soil aggregates. Eur. J. Soil Sci., 52:607-618, 2001.

SOHI, S.P.; MAHIEU, N.; ARAH, J.R.M.; POWLSON, D.S.; MADARI, B. \& GAUNT, J.L. A procedure for isolating soil organic matter fractions suitable for modeling. Soil Sci. Soc. Am. J., 65:1121-1128, 2001.

STEMMER, M.; GERZABEK, M.H. \& KANDELER, E. Organic matter and enzyme activity in particle size fractions of soils obtained after low-energy sonication. Soil Biol. Biochem., 30:9-17, 1998.

STEVENSON, F.J. Humus chemistry: Genesis, composition and reactions. 2.ed. New York, Willey \& Sons, 1994. 496p.
SWIFT, R.S. Method for extraction of IHSS soil fulvic and humic acids. In: SPARKS, D.L.; PAGE, A.L.; HELMKE, P.A.; LOEPPERT, R.H.; SOLTANPOUR, P.N.; TABATABAI, M.A.; JOHNSTON, C.T. \& SUMMER, M.E., eds. Methods of soil analysis. Part 3. Chemical methods. Madison, Soil Science Society of America Books, 1996. p.1018-1020.

SWIFT, R.S. Sequestration of carbon by soil. Soil Sci., 166:858871, 2001.

TAN, Z.X.; LAL, R.; SMECK, N.E. \& CALHOUN, F.G. Relationships between surface soil organic carbon pool and site variables. Geoderma, 121:187-195, 2004.

TRUMBORE, S. Age of soil organic matter and soil respiration: Radiocarbon constraints on belowground C dynamics. Ecol. Appl., 10:399-411, 2000.

WATTS, C.W.; CLARK, L.J.; POULTON, P.R.; POWLSON, D.S. \& WHITMORE, A.P. The role of clay, organic carbon and long-term management on mouldboard plough draught measured on the Broadbalk wheat experiment Rothamsted. Soil Use Manag., 22:334-341, 2006.

WU, T.; SCHOENAU, J.J.; LI, F.; QIAN, P.; MALHI, S.S.; SHI, Y. \& XU, F. Influence of cultivation and fertilization on total organic carbon and carbon fractions in soils from the Loess Plateau of China. Soil Till. Res., 77:59-68, 2004.

YEOMANS, J.C. \& BREMNER, J.M. A rapid and precise method for routine determination of organic carbon in soil. Comm. Soil. Sci. Plant Anal., 13:1467-1476, 1988. 